\title{
DIFICULTADES EN LA PROTECCIÓN JUDICIAL DE LOS DERECHOS HUMANOS
}

\author{
Difficulties in the Judicial Protection \\ of Human Rights
}

\author{
MARTÍN RISSO FERRAND ${ }^{1}$ \\ Universidad Católica del Uruguay \\ mrisso@ucu.edu.uy
}

Cómo citar/Citation

Risso Ferrand, M. (2016).

Dificultades en la protección judicial de los derechos humanos.

Anuario Iberoamericano de Justicia Constitucional, 20, 335-367.

doi: http://dx.doi.org/10.18042/cepc/aijc.20.12

\section{Resumen}

Partiendo de la realidad que muestra nuevos tipos de violaciones de derechos humanos, o al menos violaciones que antes no se visualizaban, se ha puesto de manifiesto, en muchos casos, la insuficiencia de los medios legislativos y administrativos habituales para superar dichos problemas. Esto exige una respuesta distinta del Poder

1 Director del Departamento de Derecho Constitucional y Derechos Humanos de la Universidad Católica del Uruguay. Profesor titular de Derecho Constitucional en pre $\neg$ grado y maestría. Ha sido decano de la Facultad de Derecho de dicha Universidad, desde 1999 hasta 2010. También ha desempeñado trabajos de asesoría para varias entidades públicas y privadas, nacionales y extranjeras, y para comisiones parlamentarias. Desde 2009 es miembro del Grupo de Justicia Constitucional, de la Fundación Konrad Adenauer, que realiza un seguimiento de la jurisprudencia constitucional e internacional en América Latina. Ha publicado varios libros sobre temas vinculados al derecho constitucional y a los derechos humanos y más de ciento cincuenta trabajos en publicaciones nacionales y extranjeras. 
Judicial, diversa a la que podría llamarse tradicional, que reformula el propio rol del juez, el principio de separación de poderes y la frontera entre lo político y lo jurisdiccional. El autor, partiendo de los antecedentes estadounidenses, se detiene en el análisis de las «sentencias estructurales» colombianas y en el «estado de cosas inconstitucional», estudiando luego algunas sentencias uruguayas en el mismo sentido. Por último se procura enfocar ciertos aspectos centrales de la nueva realidad intentando llegar a conclusiones que puedan dar algunas certezas en este proceso inacabado para la protección de los derechos humanos.

\section{Palabras clave}

Sentencias estructurales; cuestiones políticas; separación de poderes; jueces constitucionaes.

\section{Abstract}

Based on the reality that shows new types of human rights violations, or at least violations that were not visualized before, there has been shown, in many cases, the ineptness of the usual legislative and administrative means to overcome these problems. This requires a different response from de Judiciary, different from what might be called the traditional response, which recasts the role of the court itself, the principle of separation of powers and the border between politics and the judiciary. The author, based on American precedents, pauses to analyze the Colombian «structural veredicts» and the «inconstitutional state of affairs», studying some Uruguayan veredicts in the same direction. Finally, he tries to focus on certain key aspects of the new reality trying to reach some conclusions that may give some certainties in this unfinished process for the protection of human rights.

\section{Keywords}

Structural remedies; political questions; separation of powers; constitutional judges. 


\section{SUMARIO}

I. INTRODUCCIÓN. II. PLAN DE TRABAJO. III. PUNTOS DE PARTIDA. IV. LOS ANTECEDENTES ESTADOUNIDENSES. V. LOS CASOS COLOMBIANOS. VI. LA SENTENCIA DE HACINAMIENTO CARCELARIO EN URUGUAY. VII. ¿̇CUÁLES SON LOS PROBLEMAS QUE GENERA LO ANTERIOR? VIII. COMENTARIO FINAL. IX. BIBLIOGRAFÍA.

\section{INTRODUCCIÓN}

En las últimas décadas se ha puesto de manifiesto, cada vez con mayor frecuencia, la insuficiencia de los criterios que podríamos llamar tradicionales para la defensa de los derechos humanos. La complejidad y la masividad de las violaciones de derechos humanos, muchas veces referidas a los derechos económicos, sociales y culturales, pero también a los de primera generación, hacen que con frecuencia una sentencia tradicional no sea idónea para superar la situación de vulneración de derechos.

Se comenzó a admitir, entonces, una flexibilización en las nociones de legitimación activa (los criterios tradicionales suelen dejar a un número elevado de sujetos sin la debida protección de sus derechos), se aceptan las acciones de clase que avanzan en el mismo sentido y, en algunos casos, el alcance de las sentencias trasciende el o los propios casos sobre los que se pronuncian. Suele mencionarse en este sentido las sentencias de la Corte Suprema de los Estados Unidos en Brown v. Board of Education de 1954 y 1955 (Sullivan, 2004: 641)2 , así como el caso Baker (Ansolabehere, 2004: 297) ${ }^{3}$ referido a la conformación de las circunscripciones electorales.

2 En este caso, la Corte Suprema terminó con el criterio de «iguales pero separados» que permitía transporte, escuelas, etc. para blancos y afrodescendientes.

3 Este fallo terminó con el manejo arbitrario en la definición de las circunscripciones electorales en perjuicio de los afrodescendientes. 
En los últimos tiempos el Tribunal Constitucional colombiano ha dictado muchos fallos trascendentes y sin duda sugerentes para todo el continente, en los que se destacan las nociones de "estado de cosas inconstitucional» y las «sentencias estructurales», referidos, entre otros casos, al hacinamiento carcelario, la violación de derechos humanos de la población desplazada por el conflicto armado y a la atención de la salud.

También ha sido en cierta forma frecuente en nuestro continente que, aun en forma aislada o sin un desarrollo general previo, aparezcan pronunciamientos de este tipo en casi todos los países. En Uruguay el ejemplo claro lo constituye la Sentencia 41, de 8 de junio de 2009, dictada por la jueza letrada de primera instancia en lo contencioso administrativo, Cristina Cabrera, lamentablemente luego revocada por el Tribunal de Apelaciones.

\section{PLAN DE TRABAJO}

Para realizar una primera aproximación a la temática procederé de la siguiente manera:

a) Establecer algunos puntos de partida para el análisis del tema.

b) Recoger desarrollos del Tribunal Constitucional colombiano (y en sus antecedentes en el derecho norteamericano), que es el que más ha trabajado estos conceptos en nuestro continente.

c) A continuación se considerará el que a mi juicio es el mejor ejemplo de este tipo de sentencias en Uruguay.

d) Se analizará luego la problemática de la frontera entre la jurisdicción y lo político para ver hasta qué punto los nuevos desarrollos presentan diferencias importantes o si son variantes modernas dentro de los viejos problemas.

e) Por último, se intentará desarrollar algunas conclusiones.

\section{PUNTOS DE PARTIDA}

Las sentencias estructurales, y otras soluciones en la misma línea, aparecen como una necesidad o como un desarrollo de la realidad contemporánea y no pueden ser desconocidas. La negación de sentencias estructurales dejaría y deja muchas situaciones de violación clara de derechos humanos sin solución. En efecto, en casos de violaciones masivas y sistemáticas de derechos humanos, en situaciones que se arrastran en el tiempo sin soluciones razonablemente efectivas y respecto a las cuales no es lógico pensar que las autorida- 
des legislativas, administrativas o la sociedad civil encontrarán soluciones en tiempos más o menos breves, caben tres respuestas lógicas:

a) Mantenerse dentro de los criterios históricos que conducirán a pronunciamientos formales que no corregirán la situación de fondo. Esta hipótesis es inaceptable pues implica que el tribunal renunciaría a su función básica de garantía de los derechos humanos de una persona o de un grupo de personas.

b) Iniciar el camino del «estado de cosas inconstitucional» y de las «sentencias estructurales».

c) Aportar una nueva solución estratégica que, sin avanzar por el camino b) precedente, permita lograr soluciones efectivas para las violaciones de derechos humanos a las que ningún órgano jurisdiccional puede renunciar.

Así planteada la cuestión es muy claro a mi juicio que, siendo la opción a) inaceptable por implicar una renuncia a los más importantes principios de la labor del juez, solo cabe transitar por las otras opciones. Señalo esto en la medida en que podrán criticarse las soluciones estructurales y el estado de cosas inconstitucional, pero no será válido concluir en la renuncia a la defensa efectiva de los derechos humanos por parte de los tribunales.

Lamentablemente, es frecuente que en nuestro continente los críticos de las nuevas estrategias judiciales se limiten a criticarlas pero sin aportar soluciones efectivas para la problemática de fondo. Esto es incomprensible e inaceptable pues en ningún caso puede considerarse en nuestros tiempos como válido un discurso jurídico que desemboque en la no protección de los derechos humanos y, en especial, en tolerar por tiempo indefinido las violaciones de derechos humanos de colectivos que no pueden defenderse efectivamente.

Esta realidad plantea una serie de problemas extraordinariamente complejos y polémicos. A saber:

a) Abordar la problemática de sentencias no habituales, ya sean las propias sentencias estructurales colombianas o los «remedios estructurales» $\mathrm{O}$ «remedios específicos» de Estados Unidos.

Como ha desarrollado Landa (2010), el clásico modelo de control constitucional de la ley ha venido teniendo cambios en América Latina. Esto se aprecia con sentencias que se pronuncian más allá o fuera de lo demandado (ultra petita y extra petita), donde los efectos del fallo, si bien en principio son a futuro (ex nunc) también pueden ser modulados con efectos retroactivos (ex tunc) o, incluso, que dispone dejar su aplicación a futuro pero sujeta a una condición material o temporal (vacatiosententiae)y donde no solo el fallo es vinculante, sino también los fundamentos 
que expresan la razón jurídica (ratio decidendi). Asimismo, el fallo no siempre será mandatorio, sino que puede ser de apelación o exhortación al legislador a fin de que corrija el potencial vicio de inconstitucionalidad (el fallo demanda la aprobación de políticas públicas al Gobierno, las cuales deberán ser objeto de supervisión en su cumplimiento por la magistratura constitucional) o, a veces, la cosa juzgada constitucional permite la anulación de fallos de la justicia ordinaria, entre otras fórmulas. Aparecen entonces sentencias atípicas de aplicación e interpretación, con una gran pluralidad de variantes. Al respecto concluye este autor que:

[...] contemporáneamente, la jurisdicción constitucional tanto en América Latina como en Europa ya no solo se caracteriza por el monopolio para realizar el control abstracto de constitucionalidad de las leyes, sino también por las diversas formas en que puede adoptar una sentencia dictada en el marco de un proceso constitucional específico. Esta es una de las principales características que lo diferencia también de los órganos jurisdiccionales ordinarios. Con ello cada vez se va dejando atrás las formas tradicionales de las decisiones de los tribunales y cortes constitucionales, para dar paso a una serie de sentencias atípicas que responden, más que a cuestiones eminentemente teóricas, a situaciones políticas que surgen de cada realidad constitucional concreta. Particularmente en el caso de Latinoamérica, los tribunales y cortes constitucionales vienen dando respuesta a los «casos límite» que se someten a su competencia para ser resueltos, en el cual se conjugan bienes y valores constitucionales, y en el que no cabe un razonamiento y menos una forma de decisión formalista. Para lo cual, progresivamente, se viene incorporando jurisprudencialmente, con beneficio de inventario, la doctrina constitucional comparada acerca de la naturaleza, tipos, alcances y límites de las sentencias constitucionales.

b) Nuevos planteamientos basados en el principio de separación de poderes en la medida que los tribunales avanzan en un terreno tradicionalmente vedado a los jueces y reservado a las autoridades políticas y administrativas. Esto replantea simultáneamente el problema del límite o frontera entre la jurisdicción y la política.

c) La distinción entre actos con contenido ya definido (reglados) y los discrecionales (que dejan un margen variable de decisión al encargado de su aplicación) resulta de la máxima importancia. En el primer caso no se duda, en general, en que el tribunal puede ordenar el acto, hecho u omisión ajustado a derecho, pero el tema se hace más complejo con los discrecionales que han sido tradicionalmente dejados a la libre decisión política o administrativa.

d) También se distingue entre recursos (o remedies) sustitutivos y específicos. Greabe (2013: 857), reconociendo que la diferenciación es compleja, intermitente y poco funcional, distingue los recursos sustitutivos, 
cuando el demandante que sufre un daño recibe una suma de dinero, de los remedios o recursos específicos, que tienden a evitar ese intercambio y aspiran a prevenir el daño o anularlo, más que a dejarlo actuar y luego compensarlo.

En Uruguay la preferencia judicial, y a veces doctrinal, por los remedios sustitutivos llega a extremos en que se niegan otras defensas cuando los daños que se están causando o que se van a causar, son reparables. Esto se dio hace algunos años en materia de amparo, en donde algunos jueces, sin base normativa, excluían los amparos cuando los daños que se producían eran reparables. Esta práctica en general ha sido abandonada y hoy la jurisprudencia se muestra más cómoda y decidida a utilizar otros remedios que impidan o hagan cesar los daños ilegítimos.

Hay una fuerte correlación entre los actos discrecionales de los agentes individuales de gobierno que violan la constitución y los remedios constitucionales sustitutivos, debido a que dichos actos usualmente no pueden ser previstos y no se puede saber cuándo va a ocurrir, en tiempo real, la violación. Solamente puede ser realmente demostrada la vulneración de un derecho cuando la parte afectada se encuentra ya en juicio. Y los remedios para las violaciones constitucionales ya perfectamente consumadas son por naturaleza sustitutivos. Los remedios constitucionales específicos (o restitutivos en especie) son, por naturaleza, solamente aplicables a las violaciones en curso o inminentes, pero no para las violaciones ya consumadas (Greave, 2013: 860).

Otro problema, dentro de la discrecionalidad, se da cuando hay evidencia fáctica suficiente respecto a que, en caso de no intervenir el juez, se verificará la lesión de derechos humanos o la situación de lesión se mantendrá sin solución. Esto ocurre, por ejemplo, cuando se han mantenido ciertas situaciones contrarias a derecho por mucho tiempo (hacinamiento carcelario, omisiones en la asistencia médica, etc.) o cuando lo hecho por las autoridades políticas y administrativas ha sido insuficiente por lo que no cabe esperar, lógicamente, que la situación de lesión de derechos humanos vaya a cesar o a no producirse.

e) Otro problema que presentan las sentencias estructurales o similares es determinar si son útiles o no (se ha cuestionado fuertemente su utilidad) $y$, antes, definir cuál es la forma correcta de evaluarlas. Es frecuente que se señale respecto al caso Brown v. Board of Education que sus sentencias, de 1954 y 1955, no tuvieron en los hechos efectos positivos significativos: Tribe (2014: 19) señala que la Corte permitió al sur ir muy despacio e incluso la Corte tuvo un caso en 2007, de Seattle, en que aún se empleaba la raza en los casos desempate; Ackerman (20I4: I28, 232) dice que estas sentencias solo le dieron a los padres de niños afrodescen- 
dientes la posibilidad de invocar el derecho de sus hijos a ir a cualquier escuela, pero no los protegió contra las humillaciones e intimidaciones que sufrían quienes ejercían dicho derecho.

Pero todo depende de cómo se evalúen las sentencias. Rodríguez Garavito (2012) plantea dos posibilidades: a) atender a los efectos directos y palpables de las sentencias y realizar un estricto test de casualidad: a) la sentencia será eficaz si ha logrado un cambio constatable en las conductas de sus destinatarios; b) utilizar una visión constructivista de la relación entre el derecho y la sociedad. Con este enfoque las sentencias logran transformaciones sociales no solo si cambian la conducta de los grupos directamente comprendidos, sino también cuando provocan transformaciones indirectas o cuando modifican las percepciones de los actores sociales y legitima otras visiones del mundo.

Plantea el siguiente cuadro:

\begin{tabular}{lcc}
\hline \multicolumn{1}{c}{ Directos } & \multicolumn{1}{c}{ Indirectos } \\
\hline $\begin{array}{l}\text { Efectos } \\
\text { Instrumentales }\end{array}$ & $\begin{array}{c}\text { Diseño de política pública } \\
\text { ordenada por la sentencia. } \\
\text { incidir en el tema. }\end{array}$ & $\begin{array}{c}\text { Formación de grupos } \\
\text { de activistas para }\end{array}$ \\
\hline $\begin{array}{l}\text { Efectos } \\
\text { simbólicos }\end{array}$ & $\begin{array}{c}\text { Definición y visión del problema } \\
\text { como violación de derechos. }\end{array}$ & $\begin{array}{c}\text { Transformación de la opinión } \\
\text { pública sobre urgencia y } \\
\text { gravedad del problema }\end{array}$ \\
\hline
\end{tabular}

f) Por último, debe destacarse que las sentencias estructurales o similares tienen como consecuencia normal la de incidir fuertemente en los presupuestos estatales, lo que genera innumerables problemas.

\section{LOS ANTECEDENTES ESTADOUNIDENSES}

En Estados Unidos la función jurisdiccional, el rol del juez y la frontera entre la jurisdicción y la política siempre fueron temas trascendentes y han sido objeto de estudio y preocupación. Muchos autores han procurado expresar la evolución jurisprudencial señalando distintos períodos e hitos en dicho

4 Además de Rodríguez Garavito, puede verse el proyecto desarrollado por la RedDESC, Norwegian Centre for Human Rights y Dejusticia, de 2009, disponible en: http://www.escr-net.org/actions/actions_show.htm?doc. 
proceso. Por supuesto que en general no se puede hablar de períodos definidos, sino más bien de tendencias y no es posible hacer cortes muy precisos ${ }^{5}$. Con muchos matices y variantes, la jurisprudencia ha evolucionado desde la doctrina de las political questions hasta los structural remedies.

Como señala Tribe, el primer período se basó, en cierta medida, en que todo poder legítimo deriva del pueblo y debe ser controlado para preservar la libertad. Es el principio más antiguo y central del constitucionalismo americano. Pero se pensaba que para dicho control del poder solamente era necesario un pequeño número de explícitas limitaciones sustantivas y, mayormente, se creía que la libertad individual podía ser asegurada con mayor efectividad mediante la descentralización del poder (el principio de separación de poderes y la cuestión federal), que por normas expresas. Acá estamos en la jurisprudencia de la era de la Corte Marshall y hasta la guerra civil. Es interesante recordar que luego de la famosa sentencia de la Corte Suprema en el caso Marbury v. Madison, el judicial review, en general, solo se usó en pocos casos y para cuestiones federales para varias décadas.

Desde la guerra civil se empezó a cuestionar este sistema (no era suficiente la separación de poderes y la estructura federal) y se comenzó la búsqueda de otras soluciones y a desarrollar un nuevo modelo que reparaba en las limitaciones implícitas al poder del Gobierno y definía las esferas esenciales del poder individual, estadual y federal en términos de sus características esenciales y, por lo tanto, de la limitación implícita a cada uno.

En lo anterior juegan un rol trascendente las enmiendas 13,14 y 15, posteriores a la guerra civil, y el debido proceso se fue extendiendo fuera del ámbito criminal ${ }^{6}$. La jurisprudencia desarrolló dos variantes del debido proceso ${ }^{7}$ : el debido proceso instrumental y el debido proceso sustantivo. El primero de ellos, como señala Chemerinsky (2006: 545) refiere a los procedimientos que el Gobierno debe seguir para privar a un sujeto de ciertos derechos. Los temas centrales refieren a la forma de «noticia» que el Gobierno debe dar y a la forma

5 Tribe (2000: 6 y ss.), por ejemplo, distingue cinco períodos: (I) poderes separados y divididos; (II) restricciones implícitas al poder del Gobierno; (III) expectativas consolidadas; (IV) continuidad gubernamental, y (V) justicia estructural».

6 Sullivan (2004 : 448 y ss.) recuerdan el primer intento fallido en este sentido en la sentencia recaída en Slaughter-House Cases.

7 La garantía del debido proceso encuentra sus orígenes en las obras de Aristóteles y Cicerón y su más antiguo desarrollo normativo se encuentra en la Carta Magna de 1215 y en la de 1354. De Inglaterra el debido proceso pasó Estados Unidos de América, incluyéndose en las constituciones de Maryland, Pensylvania y Massachussetts, para terminar en 1791 con la enmienda $\mathrm{V}$ a la Constitución federal y luego, con la enmienda XIV (la primera refiere al Estado federal y la segunda a los estados miembros). 
de audiencia (proceso) que debe disponerse. El debido proceso sustantivo, por su parte, refiere a la adecuada razón del Gobierno para limitar los derechos en juego. En otras palabras, en este segundo debido proceso se requiere que el Gobierno justifique debidamente la privación dispuesta. La Corte Suprema, como señala este autor, ha distinguido claramente entre uno y otro. Si, por ejemplo, se quiere terminar con la custodia a que los padres tienen derecho sobre sus hijos se deberá: a) notificar al interesado y darle oportunidad de participar en una audiencia para la defensa de sus derechos (debido proceso instrumental), y b) los peticionarios de la restricción al derecho a la custodia deberán tener una buena justificación para que la misma sea aceptable (debido proceso sustantivo). El primero no ha generado mayores problemas mientras que el segundo ha sido objeto de largas discusiones.

Se entiende en este esquema que hay un límite al válido ejercicio del poder público pues de otra forma la enmienda 14 no tendría sentido, y las legislaturas de los Estados tendrían poder ilimitado y sería suficiente con decir que cualquier ley fue sancionada para preservar la moral, la salud o la seguridad de las personas. El ejercicio del poder público no tendría límites. Frente a esto, dentro del debido proceso sustantivo, se utiliza el «principio de razonabilidad». Por lo tanto y en cada caso (frente a cada ley o acto) la Corte debe preguntarse: «¿Es esta una manera justa, razonable y apropiada de utilizar el poder público, o es una interferencia irracional, innecesaria y arbitraria en el derecho del individuo a su libertad personal, familiar, laboral, etc.?» ${ }^{8}$. En el segundo caso habrá inconstitucionalidad por violación de este principio de razonabilidad.

La gran depresión, el desarrollo del new deal y otros movimientos de los años veinte y treinta impactaron fuertemente en este modelo, aportando la necesidad de defender los principios constitucionales en términos sustantivos. No se buscaba definir límites internos inherentes al poder de todas las instituciones de gobierno, sino que apuntaba a excluir el poder gubernamental de ciertas esferas, identificando islas de "libertades preferentes» o preferidas, y aislando a algunas de todas las instancias de intrusión estatal, salvo las más justificadas y apremiantes. Grandes limitaciones a la intervención económica que una vez se pensó que derivaban de la estructura interna de los poderes gubernamentales fueron reemplazadas por limitaciones más selectivas impuestas desde fuera (Tribe, 2000: 13).

La noción de "equal protection» ha ofrecido alternativas muy atractivas para el argumento constitucional: a) identificando aspectos fundamentales de

8 Claro que la Corte dijo esto en uno de los casos más criticados de la historia, Lochner v. New York, sobre el que volveré luego. 
la estructura social y legal que deberían estar igualmente abiertos para todos (oportunidades reales a la libertad), y b) utilizando criterios que impliquen reacciones contra el perjuicio racial y en general contra el trato desigual. Basta recordar una vez más el caso Brown.

Tribe (2000: 16) señala que los límites en estos nuevos modelos no son claros y que no es posible hacer clasificaciones racionales, sino más bien listas de casos o nombres. Y agrega que la reclamada intervención gubernamental ha generado una inevitable tensión con el ideal del primer modelo. La tensión es entre dividir, separar y controlar los poderes para así contener la acción gubernamental, por un lado, y la convicción de que la libertad real requiere una acción del Gobierno y no su pasividad, por otro. Pero siguiendo los conceptos históricos de Estados Unidos, muchas veces los deberes gubernamentales afirmativos fueron definidos con el antiguo lenguaje y con base en la teoría de las limitaciones legales del Estado. Así se afirmó que cuando el Gobierno se entromete respecto a ciertas expectativas e intereses de los particulares (incluso para renovar o no un derecho de un sujeto) se requiere que los afectados sean escuchados (debido proceso instrumental) y la intervención justificada (debido proceso sustantivo) antes de que el Gobierno intervenga (se acepta la intervención, pero sujeta al debido proceso). O se afirma, basándose en la cláusula constitucional de igualdad, que el Gobierno debe asegurar al menos un mínimo nivel de acceso al sistema de resolución de controversias, a la realización de elecciones políticas, a un mínimo nivel de acceso a las precondiciones materiales para el refugio y la subsistencia humana, etc. Esto es, la intervención del Gobierno se enuncia con el lenguaje del debido proceso (garantía frente a la intervención que puede ser aceptable) y el equal protection (que postula condiciones de base igualitarias u oportunidades reales para la libertad).

En cualquiera de estos modelos es claro que no se puede confiar siempre en que los agentes del Gobierno vayan a comportarse voluntariamente como lo ordena la Constitución y, además, que tanto el sistema de contralor como el cumplimiento de las obligaciones afirmativas del Gobierno pueden implicar alguna forma de intervención en los derechos de los individuos, al menos parcialmente.

Respecto a las limitaciones del poder gubernamental, desde los orígenes se aprecia que no se establecieron por confiar en la fidelidad del Legislativo o del Ejecutivo a la Constitución, sino que se quiso que el Poder Judicial federal quedara facultado para vigilar esto en los casos apropiados.

Aparece luego lo que Tribe (2000: 1371) denomina «debido proceso estructural». Bajo este enfoque, la forma en que una norma es generada - por qué clase de cuerpo gubernamental, sobre qué base probatoria y a través de qué procedimiento confiable y transparente- juega un decisivo rol en su validez. Así se ha considerado inconstitucional la prohibición de contratar 
extranjeros en la Administración Pública promulgada por el servicio civil y no por el presidente; se ha invalidado la exclusión mujeres embarazadas de más de cinco meses de cargos docentes, y se ha invalidado toda exclusión de jurados respecto a personas que tengan reparos a la pena de muerte.

En esta línea los tribunales han avanzado en su rol tradicional y dictado sentencias que podrían ser consideradas con los criterios clásicos como invasivas de las competencias de los otros poderes.

En definitiva, desde el nacimiento de la doctrina de las political questions (propias de la primera época pero siempre presentes) hasta los structural remedies, se ha desarrollado una suerte de tensión entre la primera noción, que aboga por la estricta separación de poderes y porque los jueces no ingresen en cuestiones políticas, y la segunda, que postula que es labor del juez intervenir en aquellos aspectos relevantes donde se evidencia una vulneración reiterada de derechos constitucionales de los ciudadanos, con el fin de disipar hacia el futuro los efectos negativos y consolidar una solución estructural que garantice la protección de los derechos.

Y no debe perderse de vista el tema de las competencias constitucionales que también cuestiona soluciones del estilo de los remedios estructurales. Por ejemplo, Mannin (2014: 83-84) ha señalado:

La Constitución se reveló incompleta. Incluye muchas cláusulas específicas sobre la estructura, los límites y prescribe procedimientos para el ejercicio de los poderes que confiere. Pero también deja muchos vacíos. En vez de hacernos adivinar quién llena esos vacíos, el documento en sí mismo nos lo indica. El Congreso tendrá el poder de «hacer las leyes que sean necesarias y adecuadas para el ejercicio de sus poderes y de todos los demás poderes otorgados por la Constitución al Gobierno de los Estados Unidos o a cualquier Departamento o funcionario». El resultado de esa tarea no es difícil de describir. Salvo que viole alguna otra disposición de la Constitución, cuando el Congreso especifica un medio razonable para ejercitar su propio poder o los poderes de las ramas coordinadas, las otras ramas deben respetar esa decisión. Las otras ramas no pueden evadir dicha asignación de poder a través de técnicas interpretativas que se focalizan solamente en los resultados y no en los medios que el Congreso ha determinado para ejercer el gobierno federal. Tampoco pueden reclamar una mayor autoridad para llenar los vacíos de la estructura constitucional en asuntos en los que la Constitución no es clara. En años recientes, la Corte se ha encargado de desplazar las opiniones del Congreso basadas en nociones libres sobre la separación de poderes y el federalismo. Sobre la separación de poderes James MADison escribió que «cuestiones que ocurren diariamente en el curso de la práctica prueban la obscuridad que reina en estos temas e intrigan a los grandes adeptos de la ciencia política». Pero comparada con la idea de un federalismo dual —una idea que los americanos inventaron de la nada — éste era terreno firme. 
En este proceso aparece, por supuesto, el por algunos llamado peligro de los excesos judiciales y de la «lochnerización» con el que se hace referencia al caso Lochner v. New York, de 1905, en que la Corte entendió, en forma inaceptable, que la limitación de la jornada de trabajo en la panaderías (establecimiento de topes de trabajo diario y semanal) era inconstitucional (Bernstein, 2004: 325). Estos riesgos y peligros son inevitables (es el margen de error de la función jurisdiccional y de cualquier actividad) y con ellos el juez debe convivir9. Como dijo el juez Marshall en 1821 (Cohen v.Virginia):

Es muy cierto que este tribunal no asumirá jurisdicción si no debe; pero es igualmente cierto que debe ejercer jurisdicción cuando le corresponda hacerlo. El Poder Judicial no puede, a diferencia del Legislativo, evitar una medida porque ella se acerca a los límites de la Constitución. Nosotros no podemos pasarla por alto porque es dudosa. Cualesquiera sean las dudas o dificultades que presente un caso, debemos decidirlo, si es traído a nosotros. No tenemos más derecho a declinar el ejercicio de la jurisdicción que nos es conferida, que el de usurpar la que no nos es dada. Una u otra cosa constituiría traición a la Constitución. Pueden presentarse cuestiones que de buena gana evitaríamos; pero no podemos evitarlas. Todo lo que podemos hacer es ejercitar nuestra mejor capacidad de juzgar, y conscientemente cumplir con nuestro deber.

Y todavía podría dudarse hoy si esta compleja noción de las soluciones estructurales se mantiene en la actualidad. El actual presidente de la Corte Suprema de los Estados Unidos, John Roberts, señaló al asumir que los jueces son como los umpires (jueces de béisbol) y que ellos no hacen las reglas sino que las aplican ${ }^{10}$. El rol del umpire y del juez es el de asegurar que todos jueguen bajo las mismas reglas. Agregó Roberts que como un modesto umpire su rol es aplicar la norma y decretar balls y strikes (Tribe, 2014: 283). Estas referencias parecen caminar en una línea incompatible con la jurisprudencia estructural, en que la Corte no se limita, en sentido estricto, a aplicar las normas preexistentes.

Pero también Elena Kagan, al asumir en la misma Corte en 2010, utilizó la imagen de los umpire, pero señaló que esta metáfora puede hacer pensar a la gente en que la labor del juez es meramente «robótica»y agregó que, a diferen-

9 Con el riesgo de caer en el gobierno de los jueces y en sus no deseadas consecuencias. $\mathrm{Al}$ respecto debe recordarse el trabajo clásico: Lambert (2010).

10 Como recuerdan Tribe (20I4: 300), cuando el juez Marshall escribió Marbury, hizo más que declarar qué dice la ley. El agregó que la ley está esperando que se la equipe con remedios para la violación de los derechos conferidos legalmente. Como Marshall dijo, «los derechos significan poco si su violación queda sin corregir y sancionar». 
cia del umpire, la función del juez no necesariamente es decretar balls y strikes (Tushnet, 2013: 41, 47).

Las dudas que puede generar cuál es la situación actual del modelo estructural con la actual integración de la Corte Suprema de Estados Unidos se asocian necesariamente con el rol del juez. Aunque no debo incursionar en este tema (ajeno al objeto del trabajo aunque relacionado), que por sí solo generaría muchos problemas, no se puede dejar de decir algunas palabras al respecto por su clara incidencia en el tema en análisis. Dejando el umpire y sustituyéndolo por un juez de fútbol, figura más conocida y manejable, debe señalarse que: a) no puede pensarse que dicho juez se limita automáticamente a la aplicación de normas previas, sino que por el contrario su rol es mucho más amplio (conduce el juego, valora la intencionalidad con que actúan los jugadores, administra el régimen de tarjetas amarillas y rojas procurando, además de la sanción concreta de una infracción, conducir el juego dentro de determinados cánones, etc.), y b) no puede confundirse el árbitro de fútbol con un magistrado judicial, en especial si se trata de cortes supremas o constitucionales, ya que el rol de estos, como defensores de los derechos de los individuos y en el marco del principio de separación de poderes, impide que puedan subsumirse en la simple categoría de juez de fútbol. El rol de juez además ha tenido un notable cambio y basta recordar el paso del Estado «legislativo» de derecho al Estado «constitucional» de derecho. En el primero, el juez era un mero aplicador de reglas (la boca que pronunciaba la ley en un esquema en que básicamente se usaban las técnicas de la subsunción), pero en el segundo, junto con la ley (que no desaparece del escenario) se agrega la constitución, los derechos humanos, las particularidades del caso concreto y se utilizan complejas técnicas de armonización y ponderación que han cambiado, definitivamente, el rol tradicional del juez e impiden, si es que alguna vez pudo justificarse, la comparación del magistrado judicial con un umpire o juez de fútbol (Zagrebelsky, 2007).

\section{LOS CASOS COLOMBIANOS}

Barriga Pérez (2013: 1,233) entiende que para comprender en qué consisten las sentencias estructurales colombianas hay que remitirse al derecho norteamericano en donde desde principios del siglo xx se empezó a gestar la «revolución de los derechos» como mecanismo para introducir nuevos casos y nuevos derechos en la agenda judicial de la Corte Suprema, concentrándose en la protección efectiva de los derechos individuales de los ciudadanos.

Si bien no estamos ante un fenómeno nuevo, fue el Tribunal Constitucional colombiano el que más ha venido trabajando estos problemas. Al no 
ser posible proceder a un análisis general de la jurisprudencia colombiana ${ }^{11}$, se optó por referir a tres sentencias que parecen centrales: la Sentencia 153, de 1998, sobre establecimientos carcelarios; la Sentencia 606, de 1998, respecto a la salud de los reclusos, y la Sentencia 25, de 2004, sobre poblaciones desplazadas.

Antes de ingresar en el análisis de la jurisprudencia, y como aproximación a ella, debe señalarse lo polémico del tema. Quinche y Ramírez (2010: $113,138)$, por ejemplo, luego de señalar la existencia de una suerte de tendencia mundial en el avance del control de las políticas públicas por parte de los jueces, señalan los dos principales argumentos que se han manejado contra este tipo de pronunciamientos: el primero es que violaría el principio de separación de poderes pues el juez usurparía funciones de los otros poderes; el segundo que los jueces carecen de capacidad institucional para establecer cómo debe ser una política pública. Refutan la primera crítica recurriendo el principio de separación de poderes como sistema de frenos y contrapesos que permite la verificación de la regularidad jurídica de la actuación de otros órganos (las sentencias serían una muestra de la colaboración entre los poderes), y agregan que los jueces no pueden intervenir irrestrictamente, sino que tienen límites por lo que muchas veces optan por encargar a otras autoridades ciertas definiciones. Respecto a la segunda crítica la rechazan señalando que esto pasa frecuentemente en la labor judicial y esto se supera con peritos y otros asesores.

Henao (2013: 74), por su parte, justifica las sentencias estructurales en la necesidad y obligación judicial de velar por la realización y materialización de la Constitución y en el déficit de la actuación de otras autoridades. También rechaza la crítica de la falta de idoneidad de los jueces para inmiscuirse en políticas públicas que se supera con asesoramientos y peritos.

Otros autores han realizado una clara exposición de los beneficios y de los riesgos de estas sentencias. Uprimny Yepes (2007: 65 y ss.) señala que la judicialización parcial de la vida política tiene las siguientes virtudes: a) evita los abusos de los órganos políticos y de las mayorías en contra de las minorías estigmatizadas o de individuos; b) protege los derechos humanos en una sociedad democrática; c) siguiendo a Ferrajoli, reconoce que los jueces no tienen legitimidad democrática por carecer del voto popular, pero gozan de una legitimidad democrática sustancial, en la medida en que aseguran los derechos fundamentales y protegen la continuidad e imparcialidad del proceso demo-

11 Sentencias estructurales disponibles en http://www.corteconstitucional.gov.co?relatoria: T-068/98. T-153/98. T-258/98. T-590/98. T-606/98. T-525/99. T-025/04. T-760/08. 
crático, etc. Pero los riesgos no son menores: a) sobrecarga del aparato judicial (no solo por la cantidad de asuntos, sino especialmente por su contenido y por su complejidad, un tribunal puede no ser el ámbito más apropiado para resolver el problema); b) los riesgos de error judicial en estos casos es muy grande; c) habría dos justicias, una que decide espectacularmente casos muy visibles y otra invisible y rutinaria que se tramita en forma ineficiente inequitativa; d) la judicialización de la política lleva también a la politización de la justicia, y e) muchas veces la respuesta judicial es muy lenta, etc.

Incluso no deja de llamar la atención que muchos de los defensores de las sentencias estructurales terminan haciendo matizaciones y señalando que la intervención judicial tiene límites (Quinche, 2010: 130; Henao, 2013: 77). Pero el problema es que no pueden fijarse cuáles son.

\section{A) Sentencia $153 / 98$ (hacinamiento carcelario)}

El Tribunal partió de constataciones claras: a) las condiciones de hacinamiento impiden brindarle a todos los reclusos los medios diseñados para el proyecto de resocialización (estudio, trabajo, etc.); b) la imprevisión en materia de infraestructura carcelaria y la sobrepoblación ha conducido a que los reclusos ni siquiera puedan gozar de las más mínimas condiciones para llevar una vida digna en la prisión, tales como contar con un camarote, agua suficiente, servicios sanitarios, asistencia en salud, visitas familiares en condiciones decorosas, etc.; c) el hacinamiento desvirtúa de manera absoluta los fines del tratamiento penitenciario, y d) la sobrepoblación carcelaria impide la separación de los internos por categorías.

Ha dicho el Tribunal que la racionalidad constitucional es diferente de la de las mayorías. Los derechos fundamentales son precisamente una limitación al principio de las mayorías, con el ánimo de garantizar los derechos de las minorías y de los individuos. El juez constitucional está obligado a asumir la vocería de las minorías olvidadas, es decir, de aquellos grupos que difícilmente tienen acceso a los organismos políticos.

Sobre el estado de cosas inconstitucional ha señalado el Tribunal que se usa con el fin de buscar remedio a situaciones de vulneración de los derechos fundamentales que tengan un carácter general - en tanto que afectan a multitud de personas - y cuyas causas sean de naturaleza estructural (es decir, que por lo regular no se originan de manera exclusiva en la autoridad demandada y, por lo tanto, su solución exige la acción mancomunada de distintas entidades). En estas condiciones, la Corte ha considerado que dado que miles de personas se encuentran en igual situación y que si todas acudieran a la tutela podrían congestionar de manera innecesaria la administración de justicia, lo más indicado es dictar órdenes a las instituciones oficiales competentes con el 
fin de que pongan en acción sus facultades para eliminar ese estado de cosas inconstitucional. Estas carencias de infraestructura y hacinamiento en violación de los derechos más elementales de los reclusos configuran, en forma notoria, un estado de cosas inconstitucional en el sistema penitenciario.

Con base en lo anterior, el Tribunal emitió una sentencia compleja con órdenes variadas. Entre ellas podemos destacar:

- Se ordena que se notifique acerca de la existencia del estado de cosas inconstitucional en las prisiones al presidente de la República, a los presidentes del Senado de la República y de la Cámara de Representantes, a los presidentes de la Sala Penal de la Corte Suprema Justicia y de las Salas Administrativa y Jurisdiccional Disciplinaria del Consejo Superior de la Judicatura, al Fiscal General de la Nación, a los gobernadores y los alcaldes, a los presidentes de las Asambleas Departamentales y de los Concejos Distritales y Municipales y a los personeros municipales.

- Revoca varias sentencias que denegaron solicitudes de tutela interpuestas por varios reclusos y, en su lugar, concede los amparos solicitados.

- Ordena a varias autoridades que elaboren, en un término de tres meses a partir de la notificación de la sentencia, un plan de construcción y refacción carcelaria tendente a garantizar a los reclusos condiciones de vida dignas en los penales.

- Dispone que la Defensoría del Pueblo y la Procuraduría General de Nación ejercerá una supervigilancia sobre el punto anterior.

- Ordena al Ministerio de Justicia y del Derecho, al Instituto Nacional Penitenciario y Carcelario (INPEC) y al Departamento Nacional de Planeación la realización total del plan de construcción y refacción carcelaria en un término máximo de cuatro años, de conformidad con lo establecido en el Plan Nacional de Desarrollo e Inversiones.

- Ordena al INPEC y al Ministerio de Justicia y del Derecho la suspensión inmediata de la ejecución del contrato de remodelación de las celdas de la Cárcel Distrital Modelo de Santafé de Bogotá, etc.

No es necesario comentar el contenido de la sentencia en tanto expide órdenes concretas y específicas a diversas autoridades, con mandatos de hacer precisos. Y, por supuesto, es evidente el impacto en el presupuesto nacional que implica el pronunciamiento del Tribunal.

\section{B) Sentencia 606/98 (salud de reclusos)}

En esta sentencia el Tribunal parte de que el Estado asumió la responsabilidad integral por el cuidado, prevención, conservación y recuperación 
de la salud de los internos, independientemente de que estos se encuentren privados de la libertad a título preventivo o de pena. Y señaló que parte fundamental del conjunto de prestaciones que en el plano del servicio médico deben asumir los establecimientos carcelarios está constituida por la oportuna práctica de los exámenes y pruebas técnicas que permitan establecer o descartar si la persona presenta cierta afección o irregularidad en su estructura corporal o funcional en cualquiera de los múltiples aspectos integrantes del equilibrio orgánico. En efecto, no se requiere, para tener derecho a la previa verificación —en su caso especializada - sobre la presencia de una cierta anomalía, disfunción o patología, que el individuo muestre síntomas tan graves como para temer que su vida corre peligro. Es el sistema carcelario el que tiene a su cargo propiciar con eficiencia y de manera oportuna los mecanismos indispensables para esclarecer el estado real en que se encuentra el recluso, para prodigarle los cuidados médicos, asistenciales, terapéuticos o quirúrgicos, según el caso, y garantizarle así la preservación de una vida digna durante su permanencia en el penal.

Luego de constatar violaciones evidentes a estas obligaciones y lesiones a los derechos de los reclusos que manifiestan un estado de cosas inconstitucional, el Tribunal dispuso: a) que se revocan las sentencias denegatorias del amparo; b) se concede la tutela de los derechos a una vida digna, a la salud y a la integridad personal del demandante, y se ordena al INPEC que, por conducto de la dirección de la Penitenciaría Nacional de Cúcuta, dentro de las cuarenta y ocho horas siguientes a la notificación del presente fallo, disponga la efectiva atención médica del recluso, la práctica de la radiografía de columna que requiere, la evaluación de la misma, el suministro de los medicamentos y la iniciación y culminación de las terapias que el médico especialista considere necesarios; c) declara que, en materia de salud y asistencia médica y suministro de medicamentos al personal recluido en las cárceles del país, esa y anteriores providencias de la Corte han puesto en evidencia un estado de cosas inconstitucional que se precisa resolver; d) ordena al INPEC que, en coordinación con los ministerios de Hacienda, Salud y de Justicia y del Derecho y con el Departamento Nacional de Planeación, inicie, a más tardar dentro de las cuarenta y ocho horas siguientes a la notificación de la sentencia, los trámites administrativos, presupuestales y de contratación que sean indispensables para constituir o convenir un sistema de seguridad social en salud, bajo la modalidad subsidiada, que deberá estar operando plenamente en un término que no podrá exceder del 31 de marzo de 1999 y que cobije a la totalidad de los centros de reclusión del país, para detenidos y condenados, y d) establece cuáles serán las autoridades responsables del cumplimiento de la sentencia. 


\section{C) Sentencia 25/04 (población desplazada por el conflicto armado)}

Abordando un problema de gran trascendencia en Colombia, como lo es la situación de la población desplazada por el conflicto armado, ha señalado el Tribunal sobre la legitimación activa de los proponentes que dada la condición de extrema vulnerabilidad de la población desplazada, no solo por el hecho mismo del desplazamiento, sino también porque en la mayor parte de los casos se trata de personas especialmente protegidas por la Constitución — tales como mujeres cabeza de familia, menores de edad, minorías étnicas y personas de la tercera edad-, la exigencia de presentar directamente o a través de abogado las acciones de tutela para la protección de sus derechos, resulta excesivamente onerosa para estas personas. Es por ello que las asociaciones de desplazados, que se han conformado con el fin de apoyar a la población desplazada en la defensa de sus derechos, pueden actuar como agentes oficiosos de los desplazados. Tales organizaciones estarán legitimadas para presentar acciones de tutela a favor de sus miembros bajo las siguientes condiciones: a) que se haga a través de su representante legal, acreditando debidamente su existencia y representación dentro del proceso de tutela; b) que se individualice, mediante una lista o un escrito, el nombre de los miembros de la asociación a favor de quienes se promueve la acción de tutela, y c) que no se deduzca de los elementos probatorios que obran en el proceso que el agenciado no quiere que la acción se interponga en su nombre.

Dentro de los factores valorados por la Corte para definir si existe un estado de cosas inconstitucional, caben destacar la vulneración masiva y generalizada de varios derechos constitucionales que afecta a un número significativo de personas; la prolongada omisión de las autoridades en el cumplimiento de sus obligaciones para garantizar los derechos; la adopción de prácticas inconstitucionales, como la incorporación de la acción de tutela como parte del procedimiento para garantizar el derecho conculcado; la no expedición de medidas legislativas, administrativas o presupuestales necesarias para evitar la vulneración de los derechos; la existencia de un problema social cuya solución compromete la intervención de varias entidades, requiere la adopción de un conjunto complejo y coordinado de acciones y exige un nivel de recursos que demanda un esfuerzo presupuestal adicional importante, $y$, finalmente, si todas las personas afectadas por el mismo problema acudieran a la acción de tutela para obtener la protección de sus derechos, se produciría una mayor congestión judicial.

En consecuencia, el Tribunal ordenó, entre otras cosas y según el caso, que se diseñen y pongan en marcha las políticas, planes y programas que garanticen de manera adecuada los derechos fundamentales cuyo goce efectivo depende de la superación del estado de cosas inconstitucional; se destinen los 
recursos necesarios para garantizar la efectividad de tales derechos; se modifiquen las prácticas, las fallas de organización y de procedimiento que resultan violatorias de la Constitución; se reforme el marco jurídico cuyas falencias han contribuido al estado de cosas inconstitucional, y se realicen los trámites administrativos, presupuestales y de contratación que sean indispensables para superar la vulneración de los derechos.

Existen dos clases de deberes para el Estado. Por una parte, debe adoptar e implementar las políticas, programas o medidas positivas para lograr una igualdad real de condiciones y oportunidades entre los asociados y al hacerlo, dar cumplimiento a sus obligaciones constitucionales de satisfacción progresiva de los derechos económicos, sociales y culturales básicos de la población - en aplicación de lo que la jurisprudencia constitucional ha denominado «cláusula de erradicación de las injusticias presentes»—. Y, por otra, debe abstenerse de adelantar, promover o ejecutar políticas, programas o medidas ostensiblemente regresivos en materia de derechos económicos, sociales y culturales que conduzcan clara y directamente a agravar la situación de injusticia, de exclusión o de marginación que se pretende corregir, sin que ello impida avanzar gradual y progresivamente hacia el pleno goce de tales derechos.

El Tribunal ha emitido dos tipos de órdenes, dependiendo de la magnitud del problema que genera la vulneración de los derechos objeto de tutela. Así, ha proferido órdenes de ejecución simple, generalmente referidas a órdenes de abstención o de acción que pueden ser efectuadas por una autoridad sin el concurso de otras, pero también ha dictado órdenes complejas, que exigen procesos de ejecución compleja, involucran a varias autoridades y requieren acciones coordinadas.

En definitiva, el Tribunal resolvió: a) declarar la existencia de un estado de cosas inconstitucional en la situación de la población desplazada debido a la falta de concordancia entre la gravedad de la afectación de los derechos reconocidos constitucionalmente y desarrollados por la ley, de un lado, y el volumen de recursos efectivamente destinado a asegurar el goce efectivo de tales derechos y la capacidad institucional para implementar los correspondientes mandatos constitucionales y legales, de otro lado; b) comunicar dicho estado de cosas inconstitucional al Consejo Nacional para la Atención Integral a la Población Desplazada por la Violencia, para que dentro de la órbita de su competencia y en cumplimiento de sus deberes constitucionales y legales verifique la magnitud de esta discordancia y diseñe e implemente un plan de acción para superarla dando especial prioridad a la ayuda humanitaria dentro de los plazos que en la propia sentencia se indican (cumplimiento de obligaciones puntuales de hacer); c) comunicar el estado de cosas inconstitucional al Ministro del Interior y de la Justicia, para que adopten las decisiones necesarias para asegurar que exista coherencia entre las obligaciones constitucional 
y legalmente definidas de atención a la población desplazada a cargo de la respectiva entidad territorial y los recursos que debe destinar para proteger efectivamente sus derechos constitucionales; d) ordenar al Consejo Nacional para la Atención Integral a la Población Desplazada por la Violencia que dentro de los tres meses siguientes a la comunicación de la presente sentencia, adopte un programa de acción, con un cronograma preciso, encaminado a corregir las falencias en la capacidad institucional, etc.

\section{D) ¿Son eficaces?}

Esta referencia a las sentencias estructurales no puede terminar sin formular una pregunta obvia. Las sentencias estructurales se originan en el fracaso de los otros poderes de gobierno y autoridades en general en solucionar ciertas violaciones de derechos humanos. Pero, ¿estas sentencias son realmente eficaces o tendrán el mismo resultado que la acción de los otros poderes? Realmente resulta básico saber si estas sentencias cambian efectivamente la situación de violación de derechos humanos o si terminan siendo más de lo mismo; esto es, decisiones estatales bien intencionadas que no pueden superar el problema. Además, ¿hasta dónde puede llegar el Tribunal en su intervención en políticas públicas?

Quinche y Rivera señalan que es difícil de definir "políticas públicas» y entienden que sería «el conjunto de actividades, decisiones o medidas diseñadas por el Estado, y en ocasiones también llevadas a cabo directamente por él, mediante las cuales se pretende intervenir en determinadas situaciones previamente identificadas - que por lo general corresponden a situaciones socialmente percibidas como problemáticas - con el propósito de cumplir determinados objetivos - que usualmente corresponden a la intención de mitigar o de corregir esas situaciones problemáticas-». Hay tres fases claras: formulación, implementación y evaluación.

¿Puede realmente un órgano jurisdiccional intervenir con efectividad en políticas públicas así definidas? Los estudios a los que he podido acceder (Atehortúa-Arredondo (2013: 121, 145; Espinosa-Menéndez, 2012: 1, 17) no son categóricos en esto y demuestran muchas insuficiencias que pueden provenir de problemas de la sentencia, pero también de lo complejo de la realidad. Este es un tema central.

A su vez, el tema presupuestal es trascendente. Los recursos del Estado son limitados, por lo que estas sentencias tendrán limitaciones presupuestales y, además, podrán generar falta de recursos para atender otros problemas generando otras violaciones de los derechos humanos.

Las sentencias estructurales colombianas son sumamente interesantes pero hay que estudiar cuáles son sus resultados. 


\section{LA SENTENCIA DE HACINAMIENTO CARCELARIO EN URUGUAY}

En lo que podríamos considerar, en líneas generales, un camino coincidente con las sentencias estructurales, aparece en 2007 la Sentencia 103/007, dictada por la jueza letrada de familia de Vigésimo Quinto Turno, Graciela Barcelona, respecto a la situación de los niños en situación de calle, en la que se advierte un contenido completo, con órdenes complejas y con órdenes simples, y con un claro objetivo de terminar con todos los casos de niños viviendo en las calles. Esta sentencia, recaída en un proceso de amparo, no fue apelada por el Estado ${ }^{12}$.

En el año 2009, los abogados Gustavo Salle y Ramiro Chimuris, invocando la representación de intereses difusos, dedujeron una acción de amparo contra el Estado en razón de la situación de violaciones de derechos humanos existente en las cárceles uruguayas. En primera instancia, por Sentencia 41, de 8 de junio de 2009, la jueza letrada de primera instancia en lo Contencioso Administrativo de Primer Turno ${ }^{13}$, Cristina Cabrera, accedió parcialmente al amparo solicitado señalando:

1. Que era aceptable la legitimación de los promotores en representación de intereses difusos en una acepción amplia. Existe un colectivo identificable, que son todos los reclusos (actuales y futuros), por lo que la legitimación invocada es ajustada a derecho.

2. Realiza un detallado estudio de las pruebas diligenciadas en el expediente, concluyendo en la existencia de graves violaciones de los derechos humanos de los reclusos, con base en el informe del relator especial de la ONU, Manfred Nowak, del director nacional de Cárceles Jorge Szacz Bernal, del comisionado parlamentario Álvaro Garcés, y otros funcionarios.

3. Constata que se acreditó que se tomaron distintas medidas para corregir la situación, pero es claro que al día de la sentencia se están violando y se seguirán violando los derechos de los reclusos (hacinamiento, sobrepoblación, agua potable, servicios sanitarios, atención de la salud, etc.).

4. Señala que «este estado de cosas no puede ser tolerado en forma indefinida, permaneciendo en la indiferencia - y por consiguiente en la omisión- de parte del resto de los actores públicos, en el cumplimiento de los mandatos que el constituyente ha puesto a su cargo». Si bien en la sentencia no hay referencias a la jurisprudencia colombiana, se aprecian

12 Sentencia disponible en: www.elderechodigital.com.uy.

13 Disponible en: www.elderechodigital.com.uy. 
claras similitudes, hasta en la referencia al «estado de cosas» que califica directamente como inconstitucional, por lo que la noción de «estado de cosas inconstitucional» está comprendida en el desarrollo argumental.

5. En definitiva, la jueza dispuso (algunas medidas simples y otras complejas) que se disponga la eliminación de los módulos metálicos del Penal de Libertad que se usaban para el alojamiento de algunos reclusos y se proceda al realojamiento de éstos en un plazo máximo de 120 días; se dispongan las medidas necesarias para eliminar el hacinamiento carcelario en los centros que padecen superpoblación en un plazo de ocho meses; se disponga la separación de los reclusos en régimen de prisión preventiva de los condenados en un lapso de ocho meses, y en lo demás rechaza la acción.

En síntesis, el enfoque y fundamento de esta sentencia va sin duda en la línea de las sentencias estructurales. La crítica que se puede realizar a la sentencia no es respecto a una eventual extralimitación o activismo, sino, quizás, por la falta de alguna otra medida concreta y por el no establecimiento de un sistema de fiscalización o supervisión de cumplimiento.

La sentencia mencionada fue revocada en segunda instancia por Sentencia 156, de 20 de julio de 2009, dictada por el Tribunal de Apelaciones en lo Civil de Tercer Turno ${ }^{14}$. La revocación se basó en lo siguiente:

1. A juicio del Tribunal no corresponde aceptar la representación de intereses difusos en la medida que se trata de un colectivo cuyos miembros son claramente identificables, lo que es diferente a la noción de «intereses difusos».

2. En el considerando III señala el Tribunal que el «amparo» procede en casos graves y de urgencia, en que existe una inminencia del daño y que presente ilegitimidad manifiesta (me permito agregar que se cumplía con esto en dichos autos). Pero recuerda luego que la ley exige para que prospere un amparo que no existan otros medios idóneos y entiende que los accionantes se limitaron a afirmar la inexistencia de otros medios (solo refieren a una denuncia penal sin fundamentar siquiera su ineficacia), lo que sería insuficiente.

3. En el considerando IV, el central, afirma que existe una política estatal en materia carcelaria, si bien reconoce que esa política no ha permitido modificar la «lamentable» situación carcelaria, aunque entiende que el

14 Disponible en: http://bjn.poderjudicial.gub.uy/BJNPUBLICA/busquedaSimple. seam. 
amparo no es la vía idónea (y agrega como tampoco lo es para solucionar otros problemas como los niños en situación de calle ${ }^{15}$ ). Las medidas necesarias para corregir la situación son de Gobierno, que considere y pondere los intereses en juego y priorice los distintos intereses. Luego invoca la noción de la auto restricción, a la que presenta como una virtud incuestionable sin demostrarlo (lo que sin duda no es correcto).

4. Por último, algunos ministros señalan que la propia regulación legal del amparo, que establece que la orden se debe cumplir en un plazo de veinticuatro horas, demuestra que esta acción no es la vía idónea en la medida que el plazo de veinticuatro horas es insuficiente.

Los comentarios elogiosos que mereció la sentencia de primera instancia no pueden trasladarse a la sentencia del Tribunal de Apelaciones. En efecto, la utilización de un sentido estricto en materia de legitimación activa va en contra de todas las tendencias internacionales (es inviable que todos los reclusos actuales y futuros promuevan a amparos; no puede resolverse este amparo para un recluso prescindiendo de la situación general; la posición del Tribunal conduciría a un inútil congestionamiento de los tribunales con miles de acciones de amparo, lo que es innecesario porque todos pueden ser resueltos en una misma sentencia). Además, es evidente que no todas las víctimas son identificables ya que se comprende a los futuros reclusos.

Asimismo, luego de mencionar los elementos necesarios para la acción de amparo que estaban presentes en el caso, termina rechazando la acción pues no se demostró que no existan otras vías idóneas. Parece que el Tribunal invierte la solución legislativa: se puede rechazar un amparo si existen otras vías idóneas, pero no porque el actor no haya acreditado su inexistencia. Solo se puede rechazar el amparo si el Tribunal señala otras vías idóneas para lograr el mismo efecto perseguido con el amparo (pero el Tribunal no señala ninguna). Además, es evidente que no existían otras vías.

En el considerando IV hay un doble error: por un lado sostiene que superar el problema no es competencia del Poder Judicial sino de las autoridades políticas y administrativas (no podría el Judicial invadir competencias de otras autoridades), mientras que por otro lado afirma que el amparo (ni en general la vía judicial) es vía idónea. En el primer caso olvida el Tribunal que el Poder Judicial es la última garantía de los derechos humanos y que ninguna autoridad política o administrativa puede invocar sus propias competencias para violar derechos humanos (esto es inconstitucional y es el Judicial quien debe

15 Ya se mencionó que el tema de los niños en situación de calle sí fue objeto de una sentencia de amparo. 
corregir la violación de la Constitución). En el segundo caso, la sentencia se enmarca dentro de una visión del amparo hoy casi superada a nivel judicial, que postula una visión antigua del rol del juez, en especial en los casos de derechos humanos, como se verá más adelante.

En cuanto al argumento de que la ley prevé órdenes de amparo con plazo de veinticuatro horas, esto no puede ser obstáculo para el acogimiento del amparo. Hay muchos amparos en que no se puede cumplir la orden en veinticuatro horas y el tribunal fija plazos acordes a la situación. Por otra parte, no debe olvidarse el «amparo constitucional», mencionado por el propio Tribunal de Apelaciones, al que no sería oponible la previsión legal.

\section{VII. ¿̇CUÁLES SON LOS PROBLEMAS QUE GENERA LO ANTERIOR?}

La realidad pone de manifiesto que hay situaciones en que los remedios tradicionales no son idóneos para superar las violaciones de derechos humanos. Esto puede derivar de situaciones nuevas (los avances de la ciencia médica, por ejemplo, plantean tratamientos impensados hasta hace poco, pero con costes económicos muy altos), otras viejas pero que no se reparaba en ellas (condiciones de reclusión) y otras producidas por las demandas individuales y sociales a los efectos de lograr mejores condiciones de vida. Esta realidad nos demuestra que el Estado está siendo incapaz, en muchos casos, de dar respuestas adecuadas a través de las funciones legislativa y administrativa, lo que conduce a una creciente demanda ante el Poder Judicial para la tutela de los derechos violados.

Es claro, a su vez, que las sentencias que podríamos llamar tradicionales, en general, no son suficientes para superar la situación de violación de derechos, por lo que se debe recurrir a nuevas alternativas, algunas de las cuales han sido mencionadas en este trabajo.

Pero esto plantea problemas de gran trascendencia tales como el rol del juez y de la propia justicia, la cuestión de las decisiones políticas o de gobierno que están fuera de la función jurisdiccional, la problemática de la distribución de competencias y su incidencia cuando de violaciones de derechos se trata y, en general, cómo se debe actuar frente a las lesiones de derechos humanos.

Montesquieu (1999: 112) dijo que «los jueces de la nación, como es sabido, no son más ni menos que la boca que pronuncia las palabras de la ley, seres inanimados que no pueden mitigar la fuerza y rigor de la ley misma». Antes había definido al poder de juzgar como casi nulo e invisible. Pero esta figura judicial, que se aproxima a la metáfora del umpire o del juez de fútbol ya mencionada, seguramente nunca fue cierta en los hechos. Los jueces siempre fueron más que seres inanimados. 
Es cierto que durante el predominio de la cultura jurídica de lo que algunos llaman Estado «legislativo» de derecho (en el que solo —o prácticamente en forma exclusiva - se aplicaba la ley, concebida como un conjunto de reglas - disposiciones que definían un supuesto de hecho al que se atribuía una consecuencia jurídica-y que se interpretaban y aplicaban conforme las técnicas de la subsunción), se pudo haber generado la imagen del juez definido por Montesquieu, pero el juez inanimado nunca existió. Y en la actualidad, con la decadencia del Estado «legislativo» y lo que parece ser la consolidación del Estado "constitucional» de derecho (en que además de la ley juega un rol básico la constitución — con sus normas de principio—, los derechos humanos y el caso a resolver; y en que se deben aplicar complejas técnicas de armonización y ponderación) ese concepto judicial no parece posible.

El principal rol de los tribunales es la protección de los derechos humanos. Son la garantía última en los casos de violaciones de derechos y no pueden renunciar a esta finalidad básica. Y si las sentencias tradicionales no son suficientes deberán buscar nuevas estrategias.

Pero aun aceptado un nuevo rol de los jueces frente a las lesiones de derechos humanos, esto no quitaría que estos no deban inmiscuirse en temas políticos, en temas reservados a la decisión de los otros poderes de gobierno. ¿Pero realmente existen estos temas en que por razones de contenido se transforman en cuestiones políticas que quedan en todos los casos, y sin excepción alguna, fuera del contralor judicial? Vanossi (2000: 154 y ss.) ha efectuado un paralelismo entre esta noción de «cuestiones políticas» y la noción del derecho administrativo de "acto de gobierno», entendiéndose este último como no procesable ante los órganos jurisdiccionales. Así como la teoría de los «actos de gobierno" parece estar hoy en retroceso (no puede confundirse la clasificación jurídica - acto legislativo, administrativo y jurisdiccional — con la política —acto de gobierno y de administración-) y, en general, gana terreno la posición que rechaza la improcesabilidad de los actos de gobierno, sustituyendo el límite por la noción de discrecionalidad, lo mismo está ocurriendo con la noción de cuestiones políticas ${ }^{16}$.

Si se comparte lo anterior, el problema no radicaría en si existe un tipo de acto o actividad jurídica exento del contralor jurisdiccional, sino que en todo acto jurídico podremos encontrar aspectos de la máxima discrecionalidad en

16 En Argentina, y como señala Ziulu (1997: 113), se aprecian tres tendencias doctrinales: a) quienes se afilian a la concepción amplia de la Corte Suprema (Bidegain, Bianchi, etc.); b) quienes la aceptan, pero postulan su limitación (Vanossi, Marienhoff, etc.), y c) quienes se oponen a la misma (Bidart Campos, Sagüés, el propio Ziulu, etc.). 
los que la justicia no podrá ingresar en su consideración con el pretexto de su control, pues dicha discrecionalidad excede la posibilidad de infracción de tipo jurídico. Supongamos una ley que establece como pena máxima de privación de libertad para determinado delito de homicidio los veinte años de reclusión; en este caso, la Corte no podrá revisar la decisión del legislador, pero no por cuestión política, sino por entrar dentro de la discrecionalidad política del legislativo. Distinto sería que el legislador estableciera la prisión perpetua o una pena que en términos reales diera el mismo resultado (por ejemplo ciento cincuenta años de privación de libertad), ya que en este caso, si la Corte comparte la posición doctrinal que postula que la Constitución uruguaya prohíbe la pena de reclusión perpetua, el legislador se habría excedido en el ejercicio de su discrecionalidad política. Otro ejemplo podría darse cuando el Parlamento censura los actos de uno o varios ministros o cuando se rompen relaciones diplomáticas. En estos casos sería difícil encontrar aspectos que no estén dentro del marco de discrecionalidad política y por ende no sean controlables, pero aun así siempre habrá un mínimo de contralor jurisdiccional posible (por razones de forma por ejemplo).

Parece bastante claro a esta altura que el contenido en sí mismo de una norma o actividad no es determinante para excluir el control jurisdiccional. Sostener esto sería abrir una puerta a la arbitrariedad, reconociendo que hay actos o actividades exentos de contralor jurisdiccional, con lo que se trastocaría totalmente las bases más elementales del Estado de derecho.

También se ha recurrido a una distinción basada en la noción de no intervención judicial frente a «facultades de otros poderes». Este concepto puede presentarse con dos variantes:

a) Una postularía que cuando una competencia ha sido atribuida en forma privativa a un órgano legislativo o administrativo no podría haber una intervención judicial. Esta posición, pese a ser claramente equivocada (nadie puede invocar la titularidad de sus competencias para vulnerar derechos humanos), ha sido muchas veces utilizada en Uruguay en materia de amparo (para negar medicamentos a enfermos que no pueden pagar por ellos o en la propia sentencia de segunda instancia sobre hacinamiento carcelario mencionada anteriormente). Esto es inaceptable. También la discrecionalidad política puede ejercerse en forma inconstitucional y en ese caso debe intervenir el Juez. Además, existen elementos claros en sentido contrario: las normas constitucionales que refieren al contralor de la regularidad constitucional de las leyes, por ejemplo, coexisten con las que atribuyen el ejercicio de la función legislativa al Poder Legislativo. 
b) La segunda apuntaría fundamentalmente a las competencias que implican discrecionalidad a cargo del titular de ellas. Se podría controlar fuera del ámbito de discrecionalidad.

Analizando esta segunda variante: ¿puede haber contralor sobre la discrecionalidad? ¿Puede un juez ordenar algo cuya decisión forma parte de la discrecionalidad de un órgano legislativo o administrativo? No cabe duda que si una autoridad omite el dictado de un acto debido (actividad reglada) o no realiza una actividad a la que está obligada o hace algo que tiene prohibido, el juez podrá dar órdenes precisas para que dicte el acto debido, cumpla la actividad superando la omisión o cese sus conductas ilícitas. Pero si la autoridad está dentro de la discrecionalidad, ¿puede el juez meterse y adoptar decisiones que impliquen tomar partido por algunas opciones dentro de un elenco de posibilidades discrecionales?

Cuando existe discrecionalidad y son posibles varias conductas de la Administración, todas lícitas, en general se ha sostenido que el Tribunal no puede inmiscuirse en el poder de decisión del titular de la potestad ni obligarlo a una alternativa específica seleccionada por el Tribunal.

Pero el error parece estar en el planteamiento del tema como hipótesis extremas y claras (discrecionalidad vs. no discrecionalidad) cuando no suelen serlo. En efecto, salvo casos muy especiales, la discrecionalidad de las autoridades está limitada, en alguna medida, por el propio ordenamiento jurídico, sea en cuanto establece los fines de la actividad, los medios que pueden usarse $y$, especialmente, con la regulación de los derechos humanos que siempre condicionará en alguna medida la potestad discrecional. Los límites a la discrecionalidad legislativa, por ejemplo, están establecidos por la propia Constitución y por la exigencia de que las limitaciones de los derechos estén fundadas en «razones de interés general» u otros conceptos que establece la Carta. O sea, la discrecionalidad política no es total.

Esto lleva en primer término a que no pueda plantearse la cuestión como compartimentos estancos y con soluciones diversas y opuestas. Cuando la Administración es titular de un deber y se le confiere un cierto grado de discrecionalidad, pueden ocurrir al menos tres cosas:

a) Que la actividad estatal sea satisfactoria para el derecho en juego.

b) Que en lugar de actuar, dentro del marco discrecional que se le confiere, el Estado opte por no hacer nada.

c) Que actúe, pero que dicha actuación sea incuestionablemente inconveniente para cumplir con los fines perseguidos y proteger los derechos en juego. Esto puede deberse a la falta de pericia e inteligencia de las autoridades que aun de buena fe toman decisiones equivocadas, o a que de 
mala fe el Estado opta por soluciones que no tutelan el derecho en juego por motivos espurios o directamente busca aparentar el cumplimiento mediante una actividad que sabe que es insuficiente para la protección de los derechos.

Salvo en la primera opción, que no genera problemas, con un enfoque tradicional, se diría que lo único que puede hacer el Tribunal es ordenar que se actúe — caso b) — o que se actúe en forma efectiva — caso c) —. Pero habiendo discrecionalidad no podría el juez sustituir a la Administración y optar entre distintas medidas posibles escogiendo las que entiende pertinentes y estableciendo un plan de acción. La discrecionalidad impediría estas soluciones.

Por supuesto que siempre se podrá recurrir a conminaciones económicas, a sentencias de indemnización de los daños y perjuicios que se causan (remedios sustitutivos), a acciones penales contra los funcionarios (eventualmente en situación de desacato), pero todas estas alternativas son sin duda insuficientes.

A esta altura puede ser interesante repasar cómo se deben encarar estos temas. Ya señalé que por ejemplo en Marbury v. Madison, el juez Marshall hizo más que «declarar» el derecho. Asimismo agregó que «los derechos significan poco si su violación queda sin corregir y sancionar». La forma correcta de encarar el estudio del caso de violaciones de derechos humanos parece ser determinar primero si efectivamente se está ante una violación de un derecho humano y, en caso de confirmarse esto, se deberá buscar cuál es el remedio con el que el juez pondrá fin a dicha situación. Y no habrá excusas que permitan al juez dejar sin protección el derecho.

Si los accionantes son titulares de un derecho o de un interés legítimo y este está siendo violado, el Tribunal deberá solucionar la cuestión adoptando las medidas que sean necesarias a estos efectos. Y estas variarán según el caso:

a) Mandatos concretos cuando la Administración esté incumpliendo una obligación específica y concreta. A veces esto se manifestará con la nulidad de un acto (legislativo o administrativo) y la imposibilidad de que se siga aplicando. Otras veces la autoridad demandada deberá realizar actos concretos y precisos (disponer el ascenso de un funcionario ilegítimamente postergado) o realizar actividades concretas y específicas (entregar ciertos medicamentos a un enfermo y hacerse cargo de los costos) o no realizar actividades prohibidas.

b) Cuando la autoridad demandada sea titular de una cierta discrecionalidad para cumplir con sus deberes, la cuestión cambia. En este caso lo lógico y acorde a las soluciones tradicionales sería que el juez ordene actuar a la autoridad omisa, aunque sin un contenido preciso para que 
ella actúe dentro de su discrecionalidad. De todas formas, el juez sí podrá establecer el marco dentro del cual debe cumplirse la orden, establecer objetivos que alcanzar e, incluso, fijar plazos para que decida y actúe.

c) Pero en caso de omisiones contumaces o cuando el Estado reiteradamente cumple en forma defectuosa o incompleta sus obligaciones dejando sin protección al derecho, o cuando hay evidencia de que el Estado no responderá en forma apropiada para poner punto final a la violación del derecho, el Tribunal deberá avanzar con soluciones concretas que achicando el marco de discrecionalidad conduzcan a la protección efectiva de los derechos en juego. Esta vía solo sería aceptable cuando razonablemente entienda el Tribunal que hay evidencia suficiente de que la Administración no ha cumplido y no cumplirá adecuadamente con órdenes de las comprendidas en el precedente punto b). Y no se podrá decir que en este caso el Tribunal se está inmiscuyendo en temas políticos o discrecionales, sino que estará ejerciendo su función jurisdiccional y protegiendo un derecho con decisiones que son las únicas que lógicamente pueden esperarse que lleguen a buen puerto.

Por supuesto que aparecerán problemas presupuestales importantes, además de que el rol tradicional del juez cambia y la frontera entre la decisión política discrecional y la jurisdiccional se hace borrosa. Pero frente a estos problemas, debe tenerse presente siempre la existencia de un derecho humano que en forma reiterada, y por haber fracasado todos los otros medios, ha quedado sin protección. La sentencia que avanza en la discrecionalidad, se hace posible cuando no hay otra solución y en la medida que el Tribunal debe cumplir con su rol básico de último defensor de los derechos de los individuos. Nadie puede invocar el ejercicio de facultades discrecionales para violar derechos humanos.

Por último, ¿̨no estaremos ante la misma duda de 1803 pero solo con un contenido distinto producto de nuestros tiempos? Si la Corte Suprema no se hubiera declarado incompetente en Marbury, se hubiera visto en la situación de expedir una orden concreta (un «writ») contra el secretario de Estado James Madison, ordenándole que completara el proceso de designación para que Marbury pudiera tomar posesión de su cargo de juez. Aunque de la lectura de la sentencia surge que esta hubiera sido la solución correcta, debemos reconocer que hubiera sido extraordinariamente difícil. La reacción contra la sentencia que se habría metido en la competencia del presidente de los Estados Unidos habría sido muy fuerte. Posiblemente todos los argumentos que hoy se esgrimen contra las sentencias estructurales se hubieran usado contra la Corte Suprema en 1803. Pero los tiempos han cambiado. Hoy nadie duda que cuando se lesiona un derecho por la omisión de realizar una actividad «debida» (sin 
margen de discrecionalidad) por la Administración, el juez debe intervenir y ordenar la conducta concreta que sea conforme a derecho y que proteja el derecho violado (¿qué otra alternativa puede haber para la protección del derecho?). Ahora las dudas se plantean respecto a las potestades discrecionales. El razonamiento debe ser el mismo de Marshall: el Tribunal debe resolver la situación de violación de un derecho y no puede escudarse en consideraciones formales para tolerar la violación de derechos humanos ni en otro tipo de dudas o excesos (Cohen v. Virginia ya citado).

Posiblemente en unos años se vean las sentencias estructurales con las mismas seguridades (sin las dudas actuales) con que hoy vemos la solución implícita en Marbury v. Madison. Y otros serán los problemas.

\section{COMENTARIO FINAL}

Las sentencias estructurales u otras soluciones que permitan alcanzar los mismos fines, pueden ser idóneas para superar la omisión de las autoridades y para corregir errores en las decisiones adoptadas por el Estado, sean estas de buena o mala fe.

Pero no debe olvidarse algo obvio: las sentencias estructurales, al igual que le ocurre a las autoridades administrativas y legislativas, chocarán a la larga con la realidad que marca la existencia de recursos escasos que no permiten solucionar todas las situaciones de violaciones de derechos humanos. Llegado a este punto solo se podrían procurar soluciones igualitarias que repartan entre toda la sociedad, adecuadamente, los perjuicios de la referida insuficiencia de recursos y que eviten que ciertos grupos se vean totalmente protegidos y otros totalmente olvidados. Tarea nada sencilla.

O sea, no debemos creer que por este camino se logrará la solución de todos los casos de violaciones de derechos humanos. Aún así, es un camino que necesariamente se debe recorrer, salvo que se encuentre otro más efectivo.

\section{BIBLIOGRAFÍA}

Ackerman, B. (2014). We the people. Vol. 3: The civil rights revolution. Harvard: The Bleknap Press, Kindle.

Ansolabehere, S. y Issacharoff, S. (2004). The Story of Baker v. Carr. Constitutional Law Stories, (297), 298.

Atehortúa-Arredondo, C. y Fuentes-Becerra, D. (2013). Efectos desapercibidos de la sentencia T025 de 2004: sobre la necesidad de una aproximación cualitativa a las 
realidades de la población en situación de desplazamiento. International Law, 22, 121-145.

Barriga Pérez, M. L. (2014). Sentencias estructurales y protección del derecho a la salud [tesis]. Lima: Pontificia Universidad Católica del Perú. Disponible en: http://tesis. pucp.edu.pe/repositorio.

Bernstein, D. E. (2004). The Story of Lochner v. New York: Impediment to the Growth of the Regulatory State. En M. C. Dorf (ed.). Constitutional Law Stories (pp. 325357). New York: Foundation Press.

Chemerinsky, E. (2006). Constitutional Law. Principles and policies. 3a ed. New York: Aspen Publishers.

Espinosa Menéndez, N., Galindo Rosero, A., Bastidas Lopera, W. y Monsalve Rojas, J. E. (2012). Estado actual de la población víctima de desplazamiento forzado en cuanto al enfoque diferencial de su atención, el derecho a la integridad, la subsistencia mínima y al ingreso económico. El Ágora USB, 12 (1), 19-46.

Greabe, J. M. (2013). Constitutional remedies and public interest balancing. William and Mary Bill of Rights Journal, 21 (5), 856-897. Disponible en: http://scholarship. law.wm.edu/wmborj.

Henao Pérez, J. C. (2013). El juez constitucional: un actor de las políticas públicas. Revista de Economía Institucional, 15 (29), 67-102. Disponible en: www.economiainstitucional.com/esp/vinculos/pdf/No29/jhenao29.pdf.

Lambert, E. (2010). El gobierno de los jueces y la lucha contra la legislación en los Estados Unidos, trad. Félix de la Fuenta. Madrid: Tecnos.

Landa, C. (2010). Las sentencias atípicas en la jurisdicción constitucional latinoamericana. Disponible en: www.juridicas.unam.mx.

Manning, J. F. (2014). The Supreme Court 2013 Term. Foreword: The means of constitutional power. Harvard Law Review, 128 (1), 2-127.

McConnell, M. W. (2004). The story of Marbury v. Madison Defeat Look Like Victory. En M. C. (ed.). Constitutional Law Stories (pp. 13-31). New York: Foundation Press.

Montesquieu (Charles de Secondant). (1999). El espiritu de las leyes. México DF: Oxford University Press.

Quinche-Ramírez, M. F. y Rivera-Rugeles, J. C. (2010). El control judicial de las políticas públicas como instrumento de inclusión de los derechos humanos. Universitas, (121), 113-137. Disponible en: www.bibliojuridica.org.

Rodríguez Garavito, C. (2012). Evaluando el impacto y promoviendo la implementación de las sentencias estructurales sobre DESC en Colombia. Disponible en: http://docs. escr-net.org/usr_doc/RODRIGUEZ-COLOMBIA-español.pdf.

Sullivan, K. M. y Gunther, G. (2004). Constitutional Law. 15th ed. New York: Foundation Press.

Tribe, L. y Matz, J. (2014). Uncertain justice. The Roberts Court and the Constitution. New York: Henry Holt, Kindle ed.

Tribe, L. (2000). American Constitutional Law, vol. I. $3^{\text {rd }}$ ed. New York: Foundation Press. Tushnet, M. (2013). In the balance. Law and politics on the Roberts court. New York: W. W. Norton; London: Kindle ed. 
Uprimny Yepes, R. (2007). La judicialización de la política en Colombia: casos, potencialidades y riesgos. Sur: Revista Internacional de Derechos Humanos, 4 (6), 53-69.

Vanossi, J. R. A. (2000). Teoría de la Constitución II. Supremacía y control de constitucionalidad. Buenos Aires: Depalma.

Zagrebelsky, G. (2007). El derecho dúctil. Madrid: Trotta.

Ziulu, A. G. (1997). Derecho Constitucional, tomo I. Buenos Aires: Depalma.

\section{JURISPRUDENCIA CITADA}

Estados Unidos. Corte Suprema de Justicia. Marbury v. Madison, 1803. En Historic Supreme Court Decisions. 50 most cited. $1^{\text {st }}$ ed. Land Mark Publications, 2011, Kindle.

Estados Unidos. Corte Suprema de Justicia. Brown v. Board of Education, 1954 y 1955. En Historic Supreme Court Decisions. 50 most cited. $1^{\text {st }}$ ed. Land Mark Publications, 2011, Kindle.

Estados Unidos. Corte Suprema de Justicia Baker v. Carr, 1962. En Historic Supreme Court Decisions. 50 most cited. $1^{\text {st }}$ ed. Land Mark Publications, 2011, Kindle.

Estados Unidos. Corte Suprema de Justicia. Lochner v. New York, 1905. En Historic Supreme Court Decisions. 50 most cited. $1^{\text {st }}$ ed. Land Mark Publications, 2011, Kindle.

Estados Unidos. Corte Suprema de Justicia. Cohen v. Virginia, 1821. Disponible en: https://www.law.cornell.edu/supremecourt/text/19/264.

Colombia. Tribunal Constitucional. Sentencia T 153/98. Disponible en: http://www. corteconstitucional.gov.co?relatoria.

Colombia. Tribunal Constitucional. Sentencia T 606/98. Disponible en: http://www. corteconstitucional.gov.co?relatoria.

Colombia. Tribunal Constitucional. Sentencia T 25/04. Disponible en: http://www.corteconstitucional.gov.co?relatoria.

Otras sentencias estructurales disponibles en: http://www.corteconstitucional.gov.co?relatoria: T-068/98. T-153/98. T-258/98. T-590/98. T-606/98. T-525/99. T-025/04. $\mathrm{T}-760 / 08$.

Uruguay. Juzgado Letrado de Primera Instancia en lo Contencioso Administrativo de Primer Turno. Salle y Otro C/ Estado. Amparo, Sentencia 41, de 8 de junio de 2009, Disponible en: www.elderechodigital.com.uy.

Uruguay. Tribunal de Apelaciones en lo Civil de Tercer Turno. Salle y Otro C/ Estado. Amparo, Sentencia 156, de 20 de junio de 2009. Disponible en: http://bjn.poderjudicial.gub.uy/BJNPUBLICA/busquedaSimple.seam.

Uruguay. Juzgado Letrado de Primera Instancia de Familia. Fiscalía en lo Civil de Tercer Turno C/ INAU y Otro. Amparo, Sentencia 103, de 11 de setiembre de 2007. Disponible en: www.elderechodigital.com.uy. 